\section{La receta Argentina en educación universitaria y sus lecciones para Chile}

\section{Por Carlos Ponce, Ph.D. en Economía, Universidad de California y académico FEN UAH}

El actual proceso de reforma del sistema de educación universitaria chilena suscita varios interrogantes y apasionados debates. con Finlandia Más allá de lo debatible de tal asociación es también frecuente -y más razonable- usar como referencia el sistema universitario argentino. El objetivo de este articulo es realizar una breve descripción del estado de la educación universitaria en dicho pais. Conocer con mayor detalle los pilares organizativos y e desempeño del sistema universitario argentino es un ejercicio út que puede ofrecer algunas valiosas enseñanzas para su vecino El sistema universitario argentino está conformado por 110 universidades de las cuales 60 son estatales, 49 privadas y 1 internacional. Las universidades estatales, aún cuando han perdido participación en el sistema, concentran el 79\% del total de los estudiantes (DIV, Departamento de Información Universitaria, 2015). Es por ello

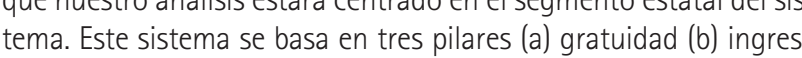
irrestrictoy (c) gobierno tri-estamental. Aún cuando estos elementos influyen simultáneamente en los logros educativos no se aborda el rol de los gobiernos universitario dado que tal aspecto ya $h$ sido discutido previamente (Observatorio Económico № 96, 2015). Animo al lector a considerar los elementos anteriores como receta argentina por medio de la cual los ingresantes al sistema universitario se convierten en egresados. La siguiente analogia puede ayudar. Cuando usted preparara una cena utiliza no solo ingredientes alimenticios sino que tambien instrucciones para transformarlos en su comida. Cuanto mejor sea su receta, màs deliciosa

¿Cuán bien ha funcionado la receta argentina? ¿Cuán sabrosa ha sido la cena? Muy pocas veces las respuestas son tan simples categoricas: la cena ha resultado desabrida y la receta un total franos pa los restentar esta afirm, permitame inspecionar algunos de los resultados aú

Si se focaliza la atención en la tasa bruta de escolarización supe rior -el cociente entre la totalidad de estudiantes $4 n$ vizestarios $y$ la totalidad de la población con edad entre los 18 y 24 años- concluira que mi anterior afirmación es falsa : Por qué? Porque la tasa argentina es similar a la de Holanda y a la de Dinamarca mientras que es más alta que la del Reino Unido y Suecia'. Más aún, mientras que Brasil y Chile tienen una población universitaria de 35 estudiantes por cada 1000 habitantes, en Argentina hay 44 estudiantes universitarios por cada 1000 habitantes? $^{2}$ universitario mediante este indicador. El producto de una univerjuzad no son sus ingresantes. Por el contrario, su resultado debo mensión las estadisticas argentinas son dececionantes. Mientras que en Brasily Chile se gradín anualmente 53 y 4,7 estudiantes cada 1000 habitantes, en Argentina solo lo hacen 27 cada 1000 habitantes.

Consideremos ahora lo que los economistas denominamos el indice de eficiencia interna (IEI) de una universidad. El IEl se define como cociente entre el número de egresados en un ano determinado y número de estudiantes que ingresaron cinco años antes. En un mundo ideal este indice debiera estar en valores cercanos a unn. Para Argentina, el lEl es de 0,27. En otras palabras, en un plazo de 5 anos, solo 27 de cada 100 alumnos consiguen graduarse4. pea, la probatidad de que un joven no finalice su carrera en un plazo de 5 anos es de $73 \%$. Aun mas, Argentina, un pais con serios problemas economicos y sociales, se permite cenas muy caras 4 de cada 100 alumnos concluren sus estudios en el phazo térico 5 años Incluso, en las universidades de mejor desempeño el apenas supera el 0,4 Como referencia, en los paises desarrollados tales guarismos se ubican entre 0.7 y 0.9 . El indice en Chile asciende a 0,6 mientras que el de Brasil se ubica en torno a 0,55 .

Usted podria argumentar que tales resultados se explican por el jcaso nivel del gasto público en educación superior. Nada más leJos de la realidad. Argentina invierte alrededor de 1,5\% de su PBI en pracion superior mientras que los palises de la OCDE ostentan un promedio de $1,6 \%$. Se puede pensar tambièn que tales indicadores con parciales y no muestran la realidad universitaria del pais. Ana-

Consion disponible es del año 2004 , reo que la misma es representativa estado actual puesto que Argentina está lejos de haber realizado un revos romedio de 20 carreras universitarias con duración teórica de 5 años, encontramos que la duración promedio real es de 8,8 años (Marquis y Toribio). En otras palabras, en promedio, los estudiantes se demoran casi 4 años más de lo esperable. En psicologia, por ejemplo, la duración media es de 9,5 años y en Abogacia de 9,8 años. Rabossi (2015) ofrece otro indicador alarmante: alrededor del $50 \%$ de los estudiantes aprueba menos de dos materias anuales y ciones más confiables sugieren que el presupuesto por graduado para el año 2014 es de 50.000 dólares laproximadamente Sún en los de pesos chilenos) ${ }^{6}$. La disperarmante. La universidad más barata de Argentina tiene un presupuesto por egresado de 19.000 dolares (aproximadamente I3 millones de pesos (hilenos), mientras

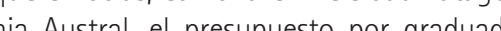
nascinde 332000 dólares (alrededor de 225 millones de pesos chilenos). AAún le parece gratis la universidad estatal en Argentina? Usted podria pensar que los economistas medimos todo en términos de eficiencia que descuidamos el impacto de las politicas públicas en el aspecto humano y social de un pais. Podria incluso argumentar que educación universitaria argentina es el motor de la igualdad social, de oportunidades y movilidad social. Nuevamente le teng malas noticias. La universidad argentina no solo es ineficiente sino que es también alta(a) Garcia de fanelli (2015) analiza, para argentinos por prupo socioconómico. Los resultados son desalentadores: $50 \%$ de ellos provienen de los dos quintiles de mayores ingresos mientras que solo 13\% lo hace los dos quintiles de menores ingresos. De manera similar, Rozada y Menedez (2001) muestran que los alumnos universitarios provienen de los sectores más adinerados de la sociedad y que más de la mitad de ellos completaron sus estudios medios en escuelas privadas. Gaggero y Rossignolo (2011) estiman que, en Argentina, los ricos captan 2,5 veces más de los beneficios de la gratuldad que los pobres. ¿Aun le parece equita¿Por qué ra riversitania argentina? ¿o estrepitoso? Los tres pilares en los que se asienta la educación universitaria contribuyen decisivamente a este pobre desempento Pero si usted osa manifestarse en contra de la gratuidad y el ingreso irrestricto, le aseguro que, como mínimo, será acusado traición a la patria

El ingreso irrestricto es solo un macabro juego de palabras. El ingreso libre no elim -

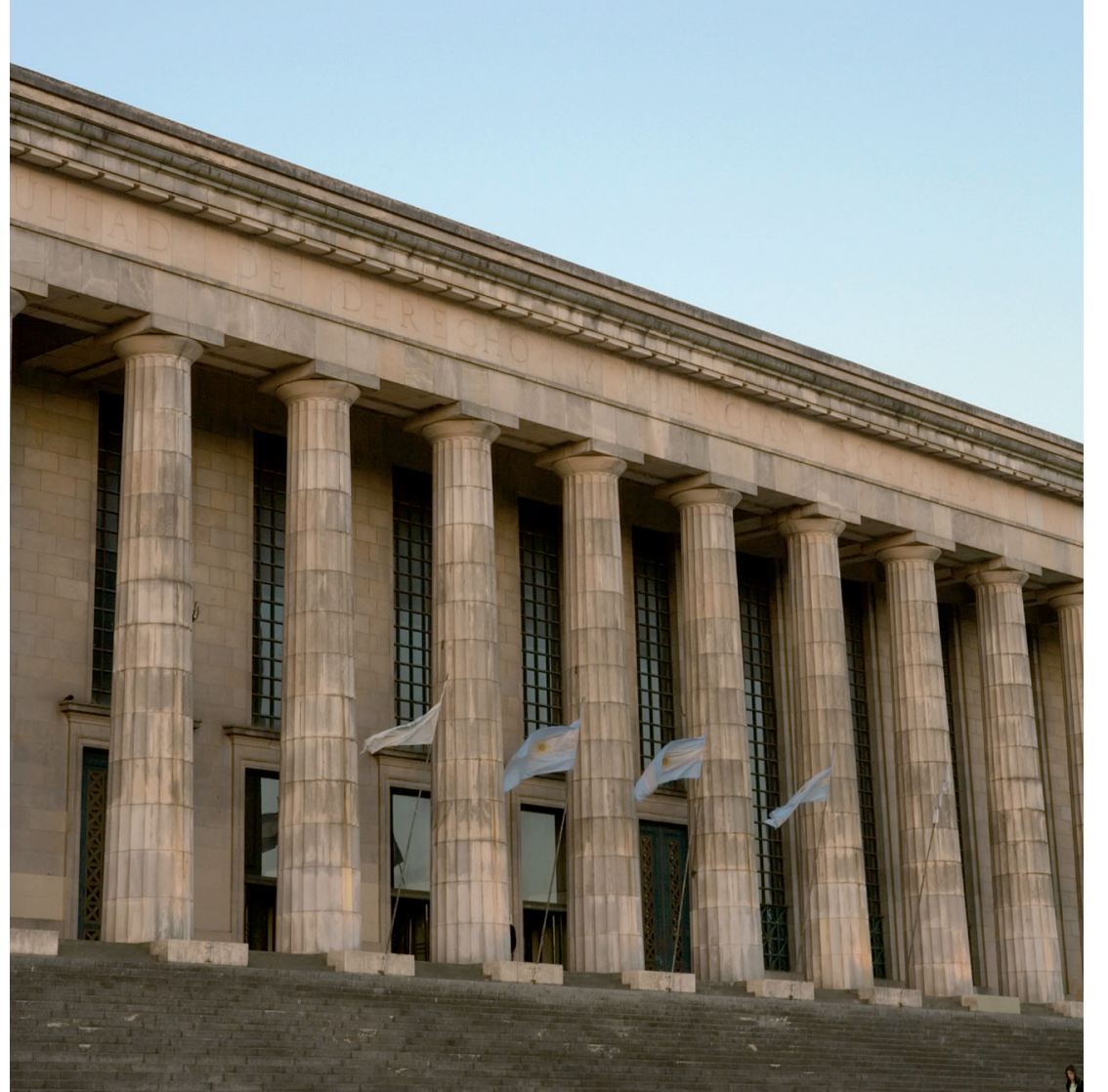

ha la ausencia de mecanismos de selección estos se implementen en un futuro cercano.

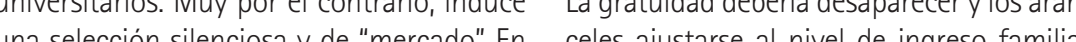
Argentina la seleción no se produce con Los alumnos más talentosos y con menores anterioridad al ingreso en la universidad - ingresos deberian ser subsididos mediante como ocurre por ejemplo en Chile con la becas que le permitan dedicarse exclusivaPSU-. El proceso de selección argentino mente a sus estudios. Los recursos liberados opera a posteriori durante los mismos es- deberian usarse de manera extensiva y efitudios universitarios. Aunque usted pueda ciente en la educación inicial y media. ingresar libremente a la universidad es muy En Argentina han ganado las consignas probable que termine abandonando sus es- el uso politicamente correcto del lenguaje. tudios si proviene de un nivel socio-econo- ¿Sucederá lo mismo en Chile? mico bajo o su formación académica previa es deficiente.

La gratuidad se ha convertido en un derecho carisimo. Usted no paga, pero termi-

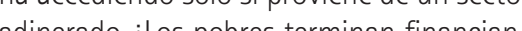
do a los ricos Mi opinión es que este efecto 1 regresivo es aún más importante en un pais como Argentina en el cual buena parte de gasto público se financia con impuestos indirectos regresivos.(En Argentina el impuesto al valor agregado es responsable del $30 \%$ de la recaudación total mientras que el impuesto a las ganancias solo contribuye con el $18 \%$.

El sistema educativo argentino necesita cambios estructurales y urgentes. Desafortunadamente, soy pesimista respecto ac
Oe

García de Fanelli (2014) "Inclusión social en la (a) Educación, Uruguay Vol. 7 № 2 "entro de Estudios de la Educación Argentina (CEA) Informe $\mathrm{N}^{\circ} 34$ A a E Eacacacion Argentina "Rabossi, M (2015) "Acceso (ilngreso?) a las. Universidades Nacionales Argentinas: Permisividad "Consecuencias" Centro de Estudios de la Educación Argentina sta es una de las estimaciones mas conservadoras. Otros expertos en el tema, estiman que dólares laproximadamente 47 millones de pesos 